\title{
Early postoperative hemodynamic instability after heart transplantation - incidence and metabolic indicators
}

\author{
Anna Kędziora ${ }^{1,2 *}$, Jacek Piątek' ${ }^{1}$, Hubert Hymczak ${ }^{3,4}$, Grzegorz Wasilewski ${ }^{1}$, Bartłomiej Guzik ${ }^{2,5}$, Rafał Drwiła ${ }^{2,3}$,
} Bogusław Kapelak ${ }^{1,2}$, Dorota Sobczyk ${ }^{2,6}$, Janusz Konstanty-Kalandyk ${ }^{1,2}$ and Karol Wierzbicki ${ }^{1,2}$

\begin{abstract}
Background: Primary graft dysfunction (PGD) is the main cause of death in the first 30 days after heart transplantation (HTX), accounting for approximately $40 \%$ of mortality. The study's primary aim was to assess the incidence of PGD, following the International Society for Heart and Lung Transplantation consensus, and to compare it with the incidence of significant postoperative hypotension despite administration of high-dose inotropes and vasoconstrictors. The secondary aim of the study was to determine changes in biochemical markers that accompany the phenomenon.
\end{abstract}

Methods: Forty-five patients who underwent HTX between 2010 and 2015 were enrolled in this study, and detailed hemodynamic and metabolic data from the first 48 postoperative hours were collected and analyzed. Hemodynamic instability was defined as significant postoperative hypotension (mean arterial pressure (MAP) $<60 \mathrm{mmHg}$ ) combined with a high inotrope score ( $>10)$. Data for long-term mortality were obtained from the population registration office.

Results: PGD incidence was relatively low (17.8\%); however, hemodynamic instability was common (40\%). Among unstable patients, MAP was insufficient for end-organ perfusion $(51.4 \pm 9.5 \mathrm{mmHg})$ but no decrease in left ventricular function was observed (cardiac index, $2.65 \pm 0.6 \mathrm{l} / \mathrm{min} / \mathrm{m} 2$; left ventricular ejection fraction, $52.9 \pm 15.5 \%$ ). Within this group, mean systemic vascular resistance index $\left(961 \pm 288 \mathrm{dyn}^{*} \mathrm{~s}^{*} \mathrm{~m} 2 / \mathrm{cm} 5\right)$ was low despite receiving high doses of vasoactive agent (norepinephrine $0.21(0.06-0.27) \mu \mathrm{g} / \mathrm{kg} / \mathrm{min}$ during first $24 \mathrm{~h}$ postoperatively and $0.21(0.01-0.27) \mu \mathrm{g} /$ $\mathrm{kg} /$ min during next $24 \mathrm{~h}$ postoperatively). After HTX, serum lactate levels were initially significantly higher in patients with hemodynamic instability $(p=0.002)$; however, impaired lactate clearance was not observed $(p=0.366)$, and lactate levels normalized within the first $24 \mathrm{~h}$ postoperatively. Postoperative hemodynamic instability altered the longterm outcome and increased 5-year mortality after $\operatorname{HTX}(p=0.034)$.

Conclusions: Hemodynamic instability is a more common phenomenon than PGD. Only early postoperative serum lactate levels correspond with hemodynamic instability following HTX. Postoperative hemodynamic instability is associated with poor long-term survival among HTX recipients.

Keywords: Heart transplantation, Primary graft failure, Hemodynamic instability, Serum lactate, Vasoplegia, Inotrope score

*Correspondence: anna.kedziora.mail@gmail.com

1 Department of Cardiovascular Surgery and Transplantology, John Paul II Hospital, 80 Pradnicka St., 31-202 Krakow, Poland

Full list of author information is available at the end of the article

\section{Background}

Recent technical developments have allowed application of novel treatment strategies for heart failure (HF) management. Left ventricular assist devices (LVADs) original author(s) and the source, provide a link to the Creative Commons licence, and indicate if changes were made. The images or other third party material in this article are included in the article's Creative Commons licence, unless indicated otherwise in a credit line to the material. If material is not included in the article's Creative Commons licence and your intended use is not permitted by statutory regulation or exceeds the permitted use, you will need to obtain permission directly from the copyright holder. To view a copy of this licence, visit http://creativecommons.org/licenses/by/4.0/. The Creative Commons Public Domain Dedication waiver (http://creativeco mmons.org/publicdomain/zero/1.0/) applies to the data made available in this article, unless otherwise stated in a credit line to the data. 
are currently implanted worldwide as a destination therapy in over $70 \%$ of cases with excellent 3-year survival for centrifugal flow devices with full magnetic levitation [1]. However, in accordance with the current European Society of Cardiology (ESC) guidelines, heart transplantation (HTX) remains the gold standard treatment option that significantly improves survival, exercise capacity, and quality of life [2]. Apart from donor shortage, the early postoperative period remains the most challenging, with the highest mortality rate of $10-15 \%$, steady throughout all transplant eras [3].

Primary graft dysfunction (PGD) is the main cause of death in the first 30 days after HTX, accounting for approximately $40 \%$ of mortality [3]. PGD incidence significantly varies across studies (from 2.3 to $28.2 \%$ ), which represents a wide range of applied definitions, even after the International Society for Heart and Lung Transplantation (ISHLT) consensus was introduced in 2014 [4]. The consensus streamlined the diagnosis of a rigorously defined impaired cardiac function and the extent of inotrope and mechanical support to be required within $24 \mathrm{~h}$ of completion of surgery [4]. Since then, only a few papers have focused on the accurately reported incidence for PGD [5-7]. Nevertheless, the initial authors hypothesis was that postoperative hemodynamic complications may be a more common phenomenon that PGD. Therefore, the primary aim of the study was to assess the incidence of PGD in accordance with the ISHLT consensus and to compare it with the incidence of significant postoperative hypotension despite administration of high-dose inotropes and vasoconstrictors within the same sample.

The reported outcomes of severe PGD cases were usually fatal, and the most common autopsy findings included reperfusion injury, ischemia, and myocyte necrosis [4]. Serum lactate levels are an indicator of tissue ischemia in many clinical settings [8]. However, postoperative hyperlactatemia is commonly observed after HTX, and levels $\geq 4 \mathrm{mmol} / \mathrm{L}$ were reported in $59.2 \%$ of recipients in one study [9]. Based on our previous findings, serum lactate levels taken immediately after HTX can be used to predict in-hospital mortality $[10,11]$. On the other hand, another study showed that extremely high lactate levels (severe hyperlactatemia defined by the authors as $>15 \mathrm{mmol} / \mathrm{L}$ ) at any time of hospitalization was associated with fatal outcomes [12]. Nevertheless, a comprehensive analysis of postoperative serum lactate levels and hemodynamic function in HTX recipients is still lacking. Therefore, the secondary aim of the study was to determine the association between lactate levels and other routinely measured biochemical markers with hemodynamic parameters within early period after HTX.

\section{Material and methods}

Forty-five patients who underwent HTX in the Department of Cardiovascular Surgery and Transplantology between 2010 and 2015 were enrolled in this retrospective study (Table 1). None of the patients were supported with LVAD prior to HTX. Detailed data were retrieved from medical records for the first $48 \mathrm{~h}$ after HTX. Data for long-term mortality were obtained from the population registration office.

PGD incidence and severity were assessed in accordance with the ISHLT consensus [4]. Hemodynamic instability was defined as any episode of mean arterial pressure (MAP) below $60 \mathrm{mmHg}$ [8] combined with high-dose inotropes and vasoconstrictors requirement (inotrope score $>10$ ) [4] or need for venoarterial extracorporeal membrane oxygenation (VA-ECMO).

\section{Intraoperative management}

All surgeries were performed via median sternotomy using the biatrial technique. All recovered hearts were protected with crystalloid cardioplegia $\left(\right.$ Celsior $\left.^{\circledR}\right)$, as described previously [9]. Sufentanil $(0.2$ to $0.5 \mu \mathrm{g} / \mathrm{kg})$ was administered for general anesthesia, followed by an induction agent (propofol 0.5 to $1 \mathrm{mg} / \mathrm{kg}$ or etomidate 0.2 to $0.4 \mathrm{mg} / \mathrm{kg}$ for unstable patients), and a non-depolarizing neuromuscular blocking agent. Arterial blood gas (ABG) analysis (including hemoglobin level, serum glucose, serum lactate, and serum potassium analyses) was performed before induction of general anesthesia, after initiation of cardiopulmonary bypass $(\mathrm{CPB})$, during $\mathrm{CPB}$, before weaning $\mathrm{CPB}$, and after $\mathrm{CPB}$. All metabolic abnormalities were corrected. Protective mechanical ventilation was carried out with $6-8 \mathrm{~mL} / \mathrm{kg}$ predicted body weight with the optimal settings of positive end-expiratory pressure and rate to prevent hypoxia, hypercarbia, and increase in pulmonary vascular resistance. Inhaled nitric oxide was used if necessary. The hemodynamic status was continuously monitored and corrected with the lowest effective dose of intravenous inotropic or vasoactive agent infusion when necessary. Levosimendan was routinely used for all patients in the first $24 \mathrm{~h}$ after induction of anesthesia $(0.1 \mu \mathrm{g} / \mathrm{kg} / \mathrm{min})$ without a loading dose.

\section{Postoperative management}

Postoperative management included continuous ECG and invasive arterial blood pressure monitoring for systolic blood pressure, diastolic blood pressure, and MAP. A Swan-Ganz catheter was used for detailed hemodynamic measurements, including central venous pressure (CVP), pulmonary artery systolic pressure (PA), pulmonary capillary wedge pressure (PCWP), cardiac output $(\mathrm{CO})$ and cardiac index $(\mathrm{CI})$, systemic vascular resistance index (SVRI), and pulmonary vascular 
Table 1 Baseline patients characteristic

\begin{tabular}{|c|c|c|c|c|}
\hline & ALL HTX RECIPIENTS & $\begin{array}{l}\text { WITH HEMODYNAMIC } \\
\text { INSTABILITY }\end{array}$ & $\begin{array}{l}\text { WITHOUT HEMODYNAMIC } \\
\text { INSTABILITY }\end{array}$ & $p$-value \\
\hline & $n=45$ & $n=18$ & $n=27$ & \\
\hline \multicolumn{5}{|l|}{ Demography } \\
\hline Sex & & & & 1.000 \\
\hline Female & $4(8.89)$ & $2(11.1)$ & $2(7.41)$ & \\
\hline Male & $41(91.1)$ & $16(88.9)$ & $25(92.6)$ & \\
\hline Age, years & $48.5(11.7)$ & $51.2(12.0)$ & $46.7(11.5)$ & 0.215 \\
\hline $\mathrm{BMl}, \mathrm{kg} / \mathrm{m}^{2}$ & $25.6(4.11)$ & $27.9(3.61)$ & $24.3(3.83)$ & 0.009 \\
\hline Hiperlipidemia & $15(33.3)$ & $6(33.3)$ & $9(33.3)$ & 1.000 \\
\hline Diabetes & $11(24.4)$ & $7(38.9)$ & $4(14.8)$ & 0.086 \\
\hline Cardiomyopathy & & & & 0.732 \\
\hline Dilated & $34(75.6)$ & $13(72.2)$ & $21(77.8)$ & \\
\hline Ischemic & $11(24.4)$ & $5(27.8)$ & $6(22.2)$ & \\
\hline \multicolumn{5}{|l|}{ Preoperative parameters } \\
\hline Urgent HTX & $36(80.0)$ & $13(72.2)$ & $23(85.2)$ & 0.449 \\
\hline iv $\mathrm{DB}^{\mathrm{a}}$ & $33(73.3)$ & $11(61.1)$ & $22(81.5)$ & 0.175 \\
\hline iv inotropic agents ${ }^{b}$ & $11(24.4)$ & $6(33.3)$ & $5(18.5)$ & 0.304 \\
\hline $\mathrm{AST}, \mathrm{U} / \mathrm{L}$ & $29.0(22.3)$ & $23.6(9.96)$ & $32.4(27.1)$ & 0.132 \\
\hline $\mathrm{ALT}, \mathrm{U} / \mathrm{L}$ & $32.1(33.3)$ & $27.2(20.1)$ & $35.2(39.6)$ & 0.382 \\
\hline TBIL, $\mu \mathrm{mol} / \mathrm{L}$ & $13.2(8.86)$ & $12.8(7.59)$ & $13.4(9.75)$ & 0.833 \\
\hline CREA, $\mu \mathrm{mol} / \mathrm{L}$ & $97.7(29.1)$ & $114(32.1)$ & $87.1(21.4)$ & 0.005 \\
\hline $\mathrm{GFR}, \mathrm{mL} / \mathrm{min} / 1.73 \mathrm{~m}^{2}$ & $77.7(20.5)$ & $65.6(18.3)$ & $85.8(17.9)$ & 0.001 \\
\hline
\end{tabular}

Number (\%), mean (SD) are presented

AST aspartate aminotransferase, $A L T$ alanine aminotransferase, TBIL total bilirubin, CREA creatinine, GFR glomerular filtration rate

${ }^{a}$ pretransplant continuous intravenous dobutamine infusion

${ }^{b}$ pretransplant continuous intravenous inotropic agents infusion (other than dobutamine)

resistance index (PVRI). Detailed data were obtained every $6 \mathrm{~h}$ (Table 2). Transthoracic echocardiography (TTE) with left ventricle ejection fraction (LVEF) assessment was performed daily. Within the first $48 \mathrm{~h}$, all patients received mycophenolate mofetil, corticosteroids, and anti-thymocyte globulin for immunosuppression induction. Calcineurin inhibitors were added in further treatment schemes. Continuous infusion of inotropic or vasoactive agents was used when necessary with the lowest effective dose and data were collected daily (Table 2). The inotrope score was established daily and calculations were made in accordance with the ISHLT consensus on PGD [4].

ABG analysis was conducted at the necessary frequency (every $2-6 \mathrm{~h}$ ), based on the patient's clinical condition. Detailed data were obtained every $6 \mathrm{~h}$ in accordance with the established protocol [10]. Creatinine (CREA), glomerular filtration rate (GFR), total bilirubin (TBIL), alanine aminotransferase (ALT), and aspartate aminotransferase (AST) levels were monitored daily. GFR was automatically calculated by the medical analytics facility based on Modification of Diet in Renal Disease (MDRD) equation.

\section{Statistical analysis}

Statistical analysis was performed using the R Statistical Software (Foundation for Statistical Computing, Vienna, Austria). Normal distribution was tested using the Shapiro-Wilk test. Continuous variables are presented as means and standard deviations $( \pm \mathrm{SD})$ or medians and quartiles (Q1-Q3). For categorical variables, numbers and proportions were reported. Parametric and nonparametric tests, when appropriate, were used for either independent samples or repeated measurements. McNemar's test was used to determine the difference between PGD and hemodynamic instability incidence. Repeated measures ANOVA and area under the curve analysis were used for comparison of biochemical measurements between groups. Univariate survival analysis for remodeling function was performed using Kaplan-Meier survival plots and log rank tests.

\section{Results}

PGD was identified in $8(17.8 \%)$ cases and mostly involved the left ventricle (6 patients, 13.3\%). In two cases (4.4\%) PGD was severe and patients required VA-ECMO support. Hemodynamic instability was more common 
Table 2 Hemodynamic parameters and inotropic and vasoactive agents requirement from first $48 \mathrm{~h}$ after HTX

\begin{tabular}{|c|c|c|c|c|}
\hline & ALL HTX RECIPIENTS & $\begin{array}{l}\text { WITH HEMODYNAMIC } \\
\text { INSTABILITY }\end{array}$ & $\begin{array}{l}\text { WITHOUT HEMODYNAMIC } \\
\text { INSTABILITY }\end{array}$ & $p$-value \\
\hline & $N=45$ & $N=18$ & $N=27$ & \\
\hline \multicolumn{5}{|l|}{ Hemodynamic parameters } \\
\hline LVEF_min, \% & $54.4(12.4)$ & $52.9(15.5)$ & $55.4(10.2)$ & 0.572 \\
\hline Cl_min, $1 / \mathrm{min} / \mathrm{m} 2$ & $2.54(0.67)$ & $2.65(0.58)$ & $2.48(0.71)$ & 0.405 \\
\hline MAP_min, mmHg & $61.8(10.8)$ & $51.4(9.49)$ & $67.8(5.75)$ & $<0.001$ \\
\hline HR_max, bpm & $103(20.9)$ & $102(21.7)$ & $104(20.9)$ & 0.765 \\
\hline SBP_min, mmHg & $94.7(12.7)$ & $84.3(11.0)$ & $101(9.43)$ & $<0.001$ \\
\hline PA_max, mmHg & $39.5(7.01)$ & $41.9(6.00)$ & $38.1(7.29)$ & 0.081 \\
\hline CVP_max, mmHg & $15.4(3.10)$ & $16.3(2.85)$ & $14.8(3.16)$ & 0.132 \\
\hline PCWP_max, mmHg & $16.8(3.02)$ & $18.2(3.30)$ & $16.0(2.60)$ & 0.039 \\
\hline SVRI_min, dyn*s*m2/cm5 & $1209(369)$ & $961(288)$ & $1328(348)$ & 0.002 \\
\hline \multicolumn{5}{|c|}{ Inotropic and vasoactive agents ${ }^{a}$} \\
\hline \multicolumn{5}{|c|}{ 0-24h after HTX } \\
\hline $\mathrm{ADR}, \mu \mathrm{g} / \mathrm{kg} / \mathrm{min}$ & $0.15(0.01-0.17)$ & $0.25(0.05-0.30)$ & $0.09(0.01-0.11)$ & 0.002 \\
\hline $\mathrm{NA}, \mu \mathrm{g} / \mathrm{kg} / \mathrm{min}$ & $0.12(0.00-0.15)$ & $0.21(0.06-0.27)$ & $0.06(0.00-0.13)$ & 0.007 \\
\hline $\mathrm{DB}, \mu \mathrm{g} / \mathrm{kg} / \mathrm{min}$ & $7.48(4.36-10.16)$ & $7.83(3.45-11.67)$ & $7.29(4.34-9.92)$ & 0.714 \\
\hline $\mathrm{MIL}, \mu \mathrm{g} / \mathrm{kg} / \mathrm{min}$ & $0.27(0.11-0.36)$ & $0.34(0.20-0.43)$ & $0.24(0.08-0.34)$ & 0.257 \\
\hline Inotrope score $\mathrm{b}^{\mathrm{b}}$ & $16.2(9.8-41.4)$ & $37.1(14.7-79.8)$ & $12.7(9.2-30.9)$ & 0.012 \\
\hline \multicolumn{5}{|l|}{ 24-48 h after HTX } \\
\hline $\mathrm{ADR}, \mu \mathrm{g} / \mathrm{kg} / \mathrm{min}$ & $0.12(0.01-0.14)$ & $0.26(0.04-0.36)$ & $0.03(0.00-0.04)$ & 0.000 \\
\hline $\mathrm{NA}, \mu \mathrm{g} / \mathrm{kg} / \mathrm{min}$ & $0.09(0.01-0.11)$ & $0.21(0.01-0.27)$ & $0.03(0.00-0.05)$ & 0.002 \\
\hline $\mathrm{DB}, \mu \mathrm{g} / \mathrm{kg} / \mathrm{min}$ & $7.30(4.30-9.89)$ & $7.64(2.14-11.98)$ & $7.13(4.24-9.51)$ & 0.955 \\
\hline $\mathrm{MIL}, \mu \mathrm{g} / \mathrm{kg} / \mathrm{min}$ & $0.24(0.10-0.36)$ & $0.30(0.13-0.40)$ & $0.20(0.09-0.32)$ & 0.120 \\
\hline Inotrope score ${ }^{b}$ & $13.3(8.6-35.5)$ & $35.1(11.9-77.4)$ & $11.3(6.6-23.1)$ & 0.011 \\
\hline
\end{tabular}

Number (\%), mean (SD) or median (Q1-Q3) are presented

$L V E F$ left ventricle ejection fraction, $C l$ cardiac index, $M A P$ mean arterial pressure, $H R$ heart rate, $S B P$ systolic blood pressure, $P A$ pulmonary artery systolic pressure, $C V P$ central venous pressure, $P C W P$ pulmonary capillary wedge pressure, $S V R I$ systemic vascular resistance index, $A D R$ epinephrine, $N A$ norepinephrine, $D B$ dobutamine, MIL milrinone

a levosimendan was routinely used for all patients for first $24 \mathrm{~h}$ after induction of anesthesia $(0.1 \mu \mathrm{g} / \mathrm{kg} / \mathrm{min})$

${ }^{b}$ inotrope score calculated in accordance with ISHLT consensus ${ }^{4}$ : (dopamine $(\times 1)+$ dobutamine $(\times 1)+$ amrinone $(\times 1)+$ milrinone $(\times 15)+$ epinephrine $(\times 100)+$ norepinephrine $(\times 100)$ with each drug dosed in $\mu \mathrm{g} / \mathrm{kg} / \mathrm{min})$

than PGD and was observed in $18(40 \%)$ patients (Fig. 1; $p=0.031)$.

Among patients with hemodynamic instability left ventricle function was not impaired postoperatively (CI $2.65 \pm 0.61 / \mathrm{min} / \mathrm{m}^{2}$; LVEF $52.9 \pm 15.5 \%$ ) (Table 2); however, MAP was markedly low and insufficient for end-organ perfusion $(51.4 \pm 9.5 \mathrm{mmHg})$. Moreover, mean SVRI was significantly lower when compared to patients without hemodynamic instability $(961 \pm 288$ vs $\left.1328 \pm 348 \mathrm{dyn}^{*} \mathrm{~s}^{*} \mathrm{~m}^{2} / \mathrm{cm}^{5 ;} p=0.002\right)$ despite administration of higher doses of norepinephrine and higher overall inotrope score (Table 2). Bacterial infection was ruled out in all of the patients based on laboratory tests results (leucocyte count, procalcitonin) obtained within analyzed period.

Postoperatively, patients with hemodynamic instability had higher and increasing creatinine levels (Fig. 2A); however, preexisting impaired renal function was observed in this group (Table 1). Postoperative liver function did not vary between the groups (Fig. 2C, D, E).

On the other hand, postoperative serum lactate levels were significantly higher in recipients with hemodynamic instability (Fig. 3A; $p=0.002$ ). Higher levels were observed among these patients upon intensive care unit admission (5.0 (4.0-7.2) vs 3.0 (1.7-6.2) mmol/L; $p=0.024)$ despite no significant difference in surgery time (320 (300-340) vs $270(210-315)$ minutes; $p=0.118)$, CPB time (135 (122-202) vs 142 (128-195) minutes; $p=0.238)$, and total ischemic time $(215(141-225)$ vs 204 (185-245) minutes; $p=0.410)$. Moreover, difference in postoperative serum lactate levels was present only within first $24 \mathrm{~h}$ after HTX (Fig. 3A), despite high-dose inotropes requirement throughout all $48 \mathrm{~h}$ of observation (Table 2). Serum lactate levels did not differ between the groups at $24 \mathrm{~h}$ after HTX (2.5 (2.2-5.3) vs 2.7 (1.5$3.6) ; p=0.174)$ and lactate clearance was surprisingly 


\section{PRIMARY GRAFT DYSFUNCTION AND HEMODYNAMIC INSTABILITY INCIDENCE}

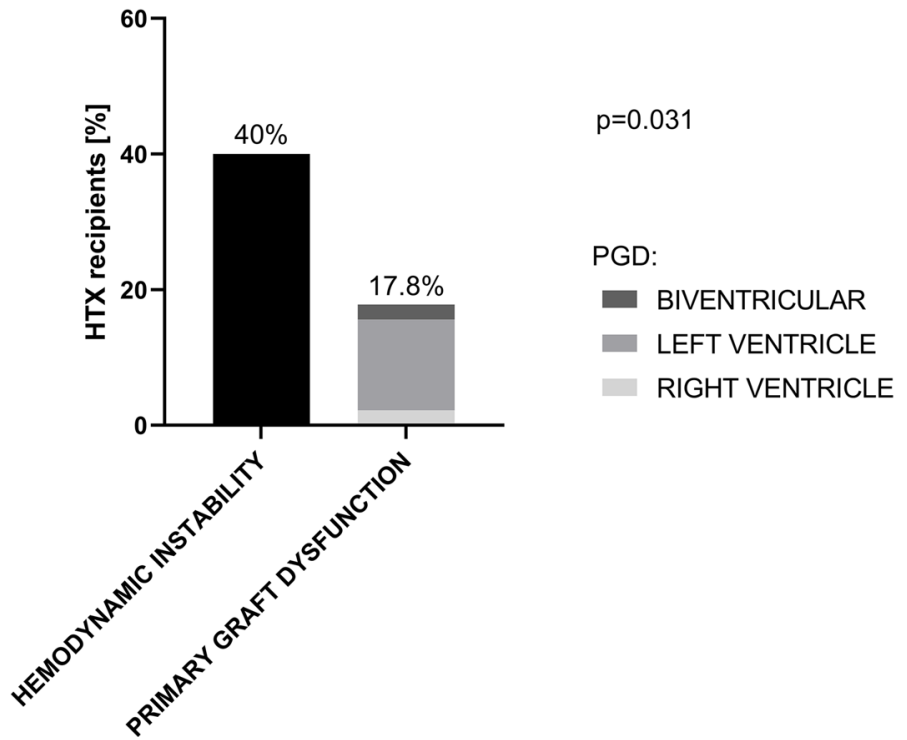

Fig. 1 Primary graft dysfunction and hemodynamic instability incidence; McNemar's test

not impaired among HTX recipients with hemodynamic instability (Fig. 3B; $p=0.366$ ).

Five in-hospital deaths were reported (11.1\%), mostly at a distant postoperative day (median: 30 [12-43] days). Three out of five $(60 \%)$ deceased patients had postoperative hemodynamic instability $(60 \%$ vs $40 \%$; $p=0.277)$. However, postoperative hemodynamic instability altered the long-term outcome and increased 5-years mortality (Fig. 4).

\section{Discussion}

Two of the largest studies that followed the ISHLT diagnostic criteria for PGD reported an incidence of $36 \%$ in the UK [5] and $15.3 \%$ for severe PGD requiring mechanical circulatory support in the American population [7]. Thus, the total PGD incidence in this study was relatively low (17.8\%) and venoatrial extracorporeal circulation was necessary only in 2 patients with severe left ventricle PGD (4.4\%). However, hemodynamic instability was more common and observed in $40 \%$ of the cases. Similar to data on PGD, patients with hemodynamic instability had declined preoperative renal function and a higher incidence of diabetes [4, 11-13]. Moreover, patients with hemodynamic instability had higher BMI, which may have resulted in a higher risk of a donor-recipient size mismatch, a known parameter for poor prognosis after HTX [5]. Although the study was not designed to assess the preoperative risk factors for hemodynamic instability but to determine postoperative biochemical markers of the phenomenon, these important baseline differences cannot be overlooked.

On the contrary to PGD, acceptable CI and LVEF were reported among patients with hemodynamic instability, presumably due to high doses of inotropic support that were used within early postoperative period (Table 2). However, the observed insufficient for end-organ perfusion MAP combined with the low SVRI despite significantly higher vasoactive agent doses (Table 2) is an interesting finding that reflects a potential vasopressordependent distributive component in hemodynamics after HTX. The activation of the systemic inflammatory response in the recipient, resulting in a vasodilated systemic circulation, has been hypothesized as one of the important aspects of pathophysiology of PGD [4]. However, due to the non-uniform diagnostic criteria, the data on this topic are sparse and a high range of reported vasoplegia syndrome incidence after HTX have been noted (11-54\%) in a few single center reports [14, 15].

Nevertheless, early and proper identification of patients with hemodynamic instability seems to be crucial, as the impact on overall long-term survival was shown in this study (Fig. 4). The long-term effect of PGD has been previously noted, and the increase in overall mortality was observed throughout the first 3 months after HTX in one paper [12]. This study showed that the impact of early postoperative hemodynamic status is even greater, and the significant decline of the survival curve can be seen up to 2 years after HTX (Fig. 4). 


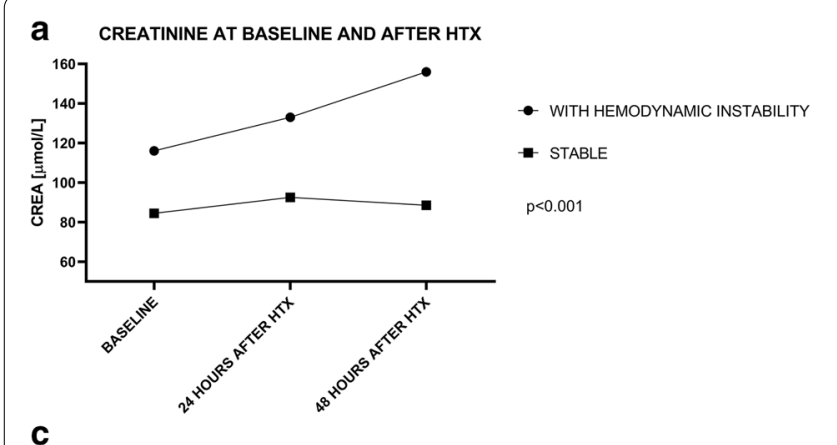

c
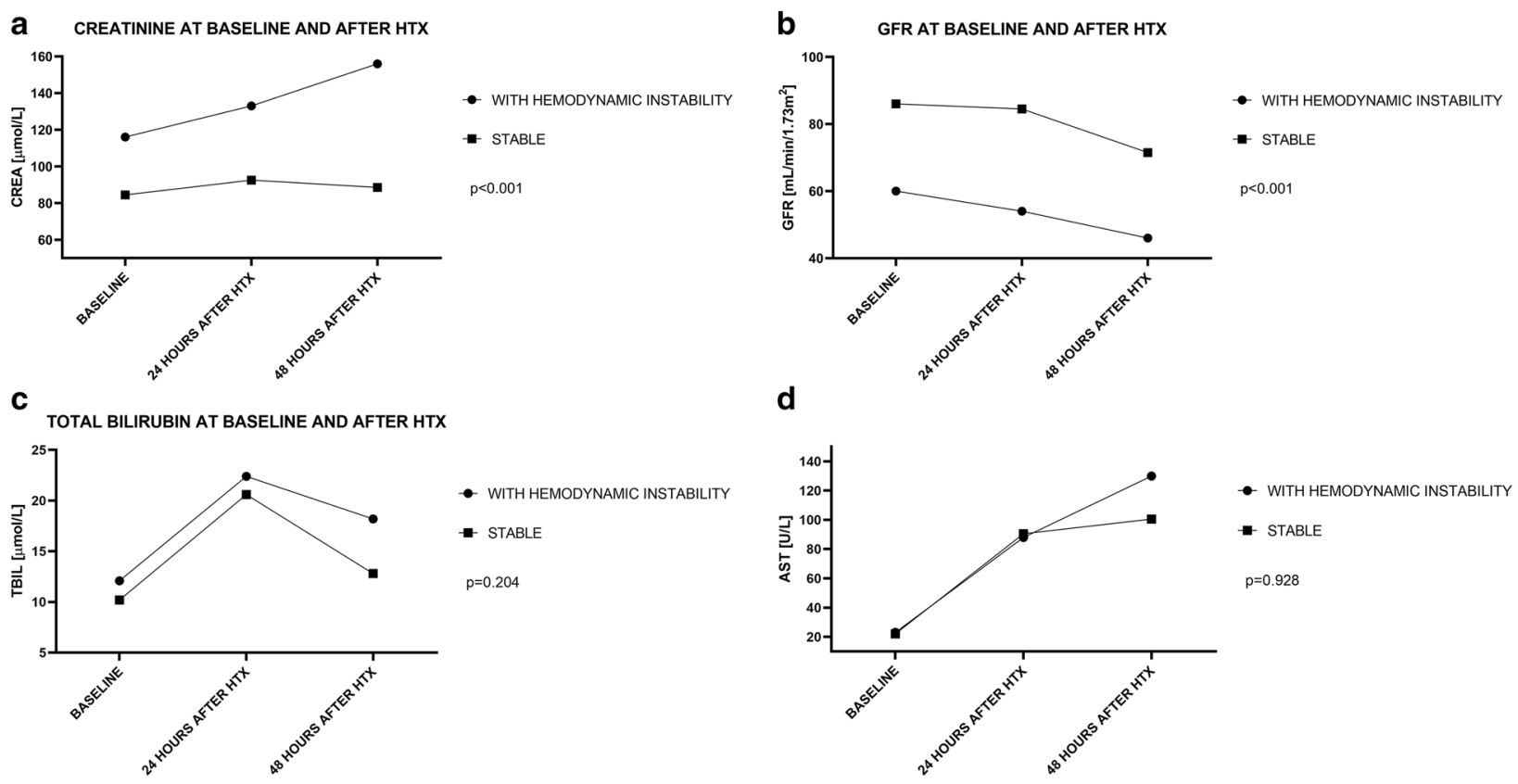

e

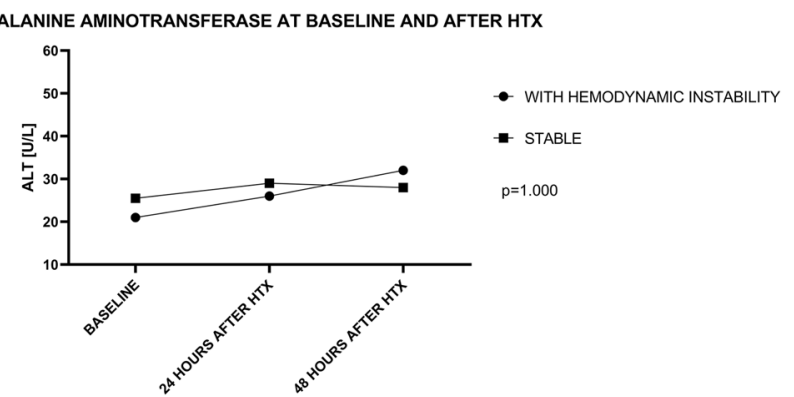

Fig. 2 Area under the curve analysis for baseline and postoperative trends: A creatinine, B GFR, C total bilirubin, D aspartate aminotransferase, E. alanine aminotransferase; median values are presented

However, there is a major gap in scientific evidence regarding the early postoperative management of HTX recipients. Most of the recommendations arise from expert consensus and no unified strategy for biochemical parameters monitoring is established [16]. As shown in this study, serum lactate levels correlate with the hemodynamic status and measurements obtained within early hours after HTX may predict hemodynamic instability and higher requirement for inotropic and vasoactive agents (Fig. 3A). Therefore, early and strict monitoring of lactate levels provides an opportunity to identify patients at higher risk of developing hemodynamic instability and to implement corrective measures to improve the outcome.

Another finding worth emphasizing is the fact that in contrast to other clinical settings (i.e., liver transplantation, mitral valve surgery, sepsis) [17-19] lactate clearance was not impaired among unstable patients.
The initial difference in serum lactate levels between the groups resolved within first $24 \mathrm{~h}$ of observation and serum lactate levels returned to normal ranges within the first $48 \mathrm{~h}$ after HTX. The cause of this unique phenomenon that distinguish HTX recipients from all previously analyzed patients hospitalized in the intensive care unit [17-19] cannot be established by this study results. The initial authors' hypothesis was that significant decline in liver and renal function, as a result of need for increased lactate utilization, will be observed, however, obtained data cannot support such statement.

The retrospective study design may raise concerns regarding the quality of evidence; however, consecutive patients were enrolled, and no patient was excluded from the analysis. Despite good adherence to the institutional postoperative management protocol regarding the timing of repeated recipients' assessment in the ICU, several anesthesiologists supervised the 
Kędziora et al. BMC Anesthesiol

(2021) 21:236

Page 7 of 9

a SERUM LACTATE LEVEL TRENDS AFTER HTX

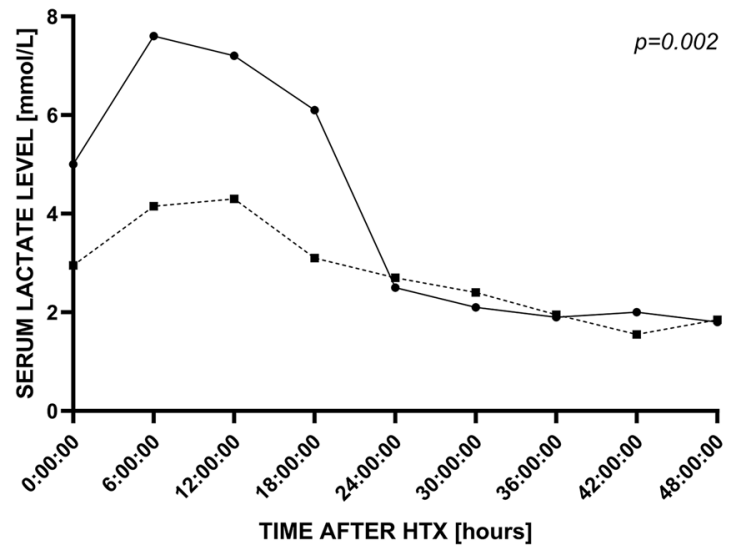

- WITH HEMODYNAMIC INSTABILITY

- STABLE

b SERUM LACTATE CLEARANCE TRENDS AFTER HTX

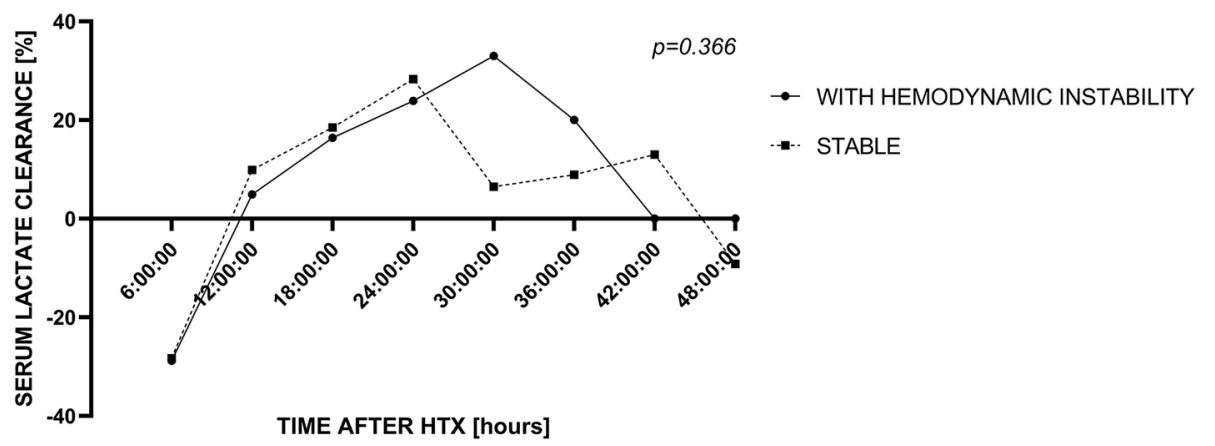

Fig. 3 Area under the curve analysis for postoperative trends: A serum lactate level, B lactate clearance; median values are presented

5-YEARS SURVIVAL AFTER HTX

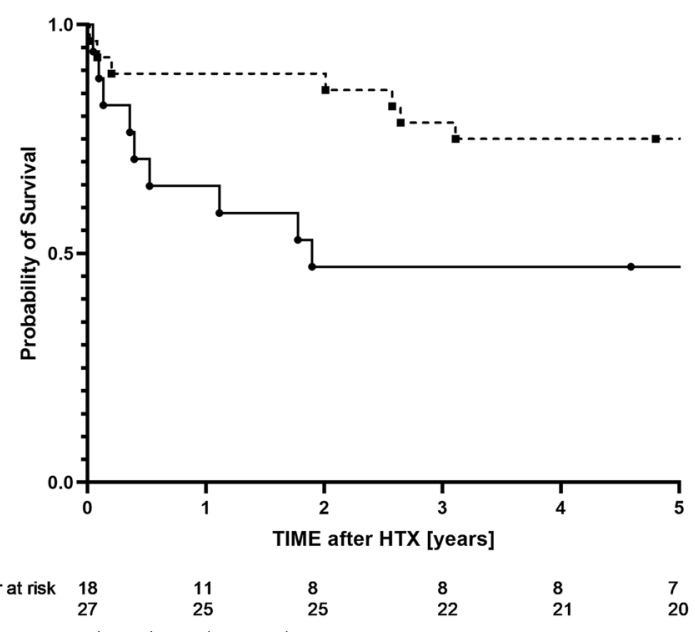

$\rightarrow$ WITH HEMODYNAMIC INSTABILITY

-.. STABLE

$p=0.034$

$\begin{array}{lllllll}\text { Number at risk } & 18 & 11 & 8 & 8 & 8 & 7 \\ & 27 & 25 & 25 & 22 & 21 & 20\end{array}$

Fig. 4 Kaplan-Meier 5-year survival analysis; log-rank test 
postoperative care within the early hours after HTX. Therefore, slight variations in decisions on fluid management and inotropic support might have been present, and investigators cannot calculate this effect in this study. Nevertheless, the major limitations of our study are the small sample size and single-center data. Study findings will require further validation in a higher volume population with a prospective design and collection of additional data on fluid management.

\section{Conclusions}

Hemodynamic instability is a more common phenomenon than PGD. Only early postoperative serum lactate levels correspond with hemodynamic parameters following HTX as impaired lactate clearance is not observed among patients with hemodynamic instability. Postoperative hemodynamic instability is associated with poor long-term survival among HTX recipients.

\begin{abstract}
Abbreviations
PGD: Primary Graft Dysfunction; HTX: Heart transplantation; MAP: Mean arterial pressure; HF: Heart failure; LVAD: Left ventricular assist device; ESC: European Society of Cardiology; ISHLT: International Society for Heart and Lung Transplantation; VA-ECMO: Venoarterial extracorporeal membrane oxygenation; ABG: Arterial blood gas; CPB: Cardiopulmonary bypass; ECG: Electrocardiography; CVP: Central venous pressure; PA: Pulmonary artery systolic pressure; PCWP: Pulmonary capillary wedge pressure; CO: Cardiac output; Cl: Cardiac index; SVRI: Systemic vascular resistance index; PVRI: Pulmonary vascular resistance index; TTE: Transthoracic echocardiography; LVEF: Left ventricle ejection fraction; CREA: Creatinine; GFR: Glomerular filtration rate; TBIL: Total bilirubin: ALT: Alanine aminotransferase; AST: Aspartate aminotransferase.
\end{abstract}

\section{Acknowledgements}

Not applicable.

\section{Authors' contributions}

AK - Conceptualization, Methodology, Data curation, Data Analysis, Writing - original draft; JP - Data curation, Writing - review \& editing; HH - Data curation, Writing - review \& editing; GW - Data curation, Writing - review \& editing; BG - Methodology, Data Analysis, Writing - review \& editing; RD - Writing - review \& editing; BK - Funding acquisition, Supervision, Writing - review \& editing; DS - Writing - review \& editing; JKK - Writing - review \& editing; KW - Conceptualization, Supervision, Methodology, Funding acquisition, Writing review \& editing. The authors read and approved the final manuscript.

\section{Funding}

The study was funded by the grant from Jagiellonian University Medical College to KW (K/ZDS/007226) and the Educatory Grant from Abbott Medical to John Paul II Hospital, Krakow, Poland.

\section{Availability of data and materials}

The datasets used and analyzed during the current study are available from the corresponding author on reasonable request.

\section{Declarations}

\section{Ethics approval and consent to participate}

The study was approved by the Jagiellonian University Bioethics Committee (122.6120.74.2017). The requirement of informed consent was waived in writing by the Jagiellonian University Bioethics Committee (122.6120.74.2017) due to the retrospective nature of the study and data anonymization prior to analysis. The study was performed in accordance with the Declaration of Helsinki and the Polish Medical Code of Ethics.

\section{Consent for publication}

Not applicable.

\section{Competing interests}

The authors declare no conflict of interest.

\section{Author details}

${ }^{1}$ Department of Cardiovascular Surgery and Transplantology, John Paul II Hospital, 80 Pradnicka St., 31-202 Krakow, Poland. ${ }^{2}$ Jagiellonian University Medical College, Krakow, Poland. ${ }^{3}$ Department of Anesthesiology and Intensive Care, John Paul II Hospital, Krakow, Poland. ${ }^{4}$ Faculty of Medicine and Health Sciences, Andrzej Frycz Modrzewski Krakow University, Krakow, Poland. ${ }^{5}$ Department of Interventional Cardiology, John Paul II Hospital, Krakow, Poland.

${ }^{6}$ Department of Cardiac and Vascular Diseases, John Paul II Hospital, Kraków, Poland.

Received: 12 March 2021 Accepted: 23 August 2021

Published online: 02 October 2021

\section{References}

1. Fernandez FG, Shahian DM, Kormos R, Jacobs JP, D'Agostino RS, Mayer JE, et al. The Society of Thoracic Surgeons National Database 2019 annual report. Ann Thorac Surg. 2019;108(6):1625-32.

2. Ponikowski P, Voors AA, Anker SD, Bueno H, Cleland JGF, Coats AJS, et al. 2016 ESC guidelines for the diagnosis and treatment of acute and chronic heart failure. Eur J Heart Fail. 2016;18(8):891-975.

3. Khush KK, Cherikh WS, Chambers DC, Harhay MO, Hayes D, Hsich E, et al. The international thoracic organ transplant registry of the International Society for Heart and Lung Transplantation: thirty-sixth adult heart transplantation report - 2019; focus theme: donor and recipient size match. J Hear Lung Transplant. 2019;38(10):1056-66.

4. Kobashigawa J, Zuckermann A, Macdonald P, Leprince P, Esmailian F, Luu $M$, et al. Report from a consensus conference on primary graft dysfunction after cardiac transplantation. J Heart Lung Transplant. Elsevier USA. 2014:33:327-40.

5. Singh SSA, Banner NR, Rushton S, Simon AR, Berry C, Al-Attar N. ISHLT primary graft dysfunction incidence, risk factors, and outcome: a UK National Study. Transplantation. 2019;103(2):336-43.

6. Avtaar Singh SS, de Das S, Rushton S, Berry C, Al-Attar N. PREDICTA: a model to predict primary graft dysfunction after adult heart transplantation in the United Kingdom. J Card Fail. 2019;25(12):971-7. https://doi. org/10.1016/j.cardfail.2019.07.009.

7. Quader M, Hawkins RB, Mehaffey JH, Mazimba S, Ailawadi G, Yarboro L, et al. Primary graft dysfunction after heart transplantation: outcomes and resource utilization. J Card Surg. 2019;34(12):1519-25. https://doi.org/10. $1111 /$ jocs. 14274

8. Minton J, Sidebotham DA. Hyperlactatemia and cardiac surgery. J Extra Corpor Technol. 2017:49(1):7-15.

9. Hoshino Y, Kinoshita O, Ono M. The incidence, risk factors, and outcomes of Hyperlactatemia after heart transplantation. Int Heart J. 2018;59(1):81-6.

10. Kędziora A, Wierzbicki K, Piątek J, Hymczak H, Górkiewicz-Kot I, Milaniak I, et al. Postoperative serum lactate levels for inhospital mortality prediction among heart transplant recipients. Ann Transplant. 2020;25:e920288-1e920288-4. https://doi.org/10.12659/AOT.920288.

11. Kędziora A, Wierzbicki K, Piętek J, Hymczak H, Górkiewicz-Kot I, Milaniak I, et al. Postoperative hyperlactatemia and serum lactate level trends among heart transplant recipients. PeerJ. 2020;2020(2):e8334.

12. Hsu YC, Hsu CH, Huang GS, Lu CC, Wu ZF, Tsai YT, et al. Extreme Hyperlactatemia after heart transplantation: one Center's experience. Transplant Proc. 2015;47(6):1945-8.

13. DeMers D, Wachs D. Physiology, Mean Arterial Pressure. In: StatPearls [Internet]. Treasure Island (FL): StatPearls Publishing; 2021. Available from: https://www.ncbi.nlm.nih.gov/books/NBK538226/. [Updated 2021 Apr 21] 
14. Wierzbicki K, Bochenek M, Kędziora A, Sojecki K, Ciołczyk-Wierzbicka D, Węgrzyn P, et al. HEART AND LUNG FAILURE, TRANSPLANTOLOGY does the postoperative troponin I blood concentration measured in the perioperative period influence hemodynamic function of a transplanted heart? Polish J Cardiothorac Surg. 2014;3(3):289-93.

15. D'Alessandro C, Golmard JL, Barreda E, Laali M, Makris R, Luyt CE, et al. Predictive risk factors for primary graft failure requiring temporary extracorporeal membrane oxygenation support after cardiac transplantation in adults. Eur J Cardiothorac Surg. 2011:40(4):962-9.

16. Cosío Carmena MDG, Gómez Bueno M, Almenar L, Delgado JF, Arizón JM, González Vilchez F, et al. Primary graft failure after heart transplantation: characteristics in a contemporary cohort and performance of the radial risk score. J Hear Lung Transplant. 2013;32(12):1187-95.

17. Chambers DC, Cherikh WS, Harhay MO, Hayes D, Hsich E, Khush KK, et al. The international thoracic organ transplant registry of the International Society for Heart and Lung Transplantation: thirty-sixth adult lung and heart-lung transplantation report-2019; focus theme: donor and recipient size match. J Hear Lung Transplant. 2019;38(10):1042-55.

18. Patarroyo M, Simbaqueba C, Shrestha K, Starling RC, Smedira N, Tang WHW, et al. Pre-operative risk factors and clinical outcomes associated with vasoplegia in recipients of orthotopic heart transplantation in the contemporary era. J Hear Lung Transplant. 2012;31(3):282-7. https://doi. org/10.1016/j.healun.2011.10.010. Epub 2011 Nov 23.

19. Chan JL, Kobashigawa JA, Aintablian TL, Li Y, Perry PA, Patel JK, et al. Vasoplegia after heart transplantation: outcomes at 1 year. In: Interactive Cardiovascular and Thoracic Surgery; 2017.
20. Costanzo MR, Dipchand A, Starling R, Anderson A, Chan M, Desai S, et al. The international society of heart and lung transplantation guidelines for the care of heart transplant recipients. J Heart Lung Transplant. Elsevier USA. 2010;29:914-56.

21. Takahashi K, Jafri SMR, Safwan M, Abouljoud MS, Nagai S. Peri-transplant lactate levels and delayed lactate clearance as predictive factors for poor outcomes after liver transplantation: a propensity score-matched study. Clin Transpl. 2019;33(7):e13613. https://doi.org/10.1111/ctr.13613. Epub 2019 Jun 20.

22. Evans AS, Levin MA, Lin H-M, Lee K, Weiner MM, Anyanwu A, et al. Prognostic value of Hyperlactatemia and lactate clearance after mitral valve surgery. J Cardiothorac Vasc Anesth. 2018;32(2):636-43.

23. Pan J, Peng M, Liao C, Hu X, Wang A, Li X. Relative efficacy and safety of early lactate clearance-guided therapy resuscitation in patients with sepsis: a meta-analysis. Medicine (Baltimore). 2019;98(8):e14453. https:// doi.org/10.1097/MD.0000000000014453.

\section{Publisher's Note}

Springer Nature remains neutral with regard to jurisdictional claims in published maps and institutional affiliations.
Ready to submit your research? Choose BMC and benefit from:

- fast, convenient online submission

- thorough peer review by experienced researchers in your field

- rapid publication on acceptance

- support for research data, including large and complex data types

- gold Open Access which fosters wider collaboration and increased citations

- maximum visibility for your research: over $100 \mathrm{M}$ website views per year

At BMC, research is always in progress.

Learn more biomedcentral.com/submissions 